\title{
Replacement of Commercial Silica by Rice Husk Ash in Epoxy Composites: A Comparative Analysis
}

\author{
Iara Janaína Fernandes ${ }^{a *} \mathbb{1}^{\circ}$, Ramon Vieira Santos ${ }^{b}$, Emanuele Caroline Araujo dos Santos ${ }^{a}$, Tatiana \\ Louise Avila Campos Rocha ${ }^{c}$, Nei Sebastião Domingues Junior ${ }^{b}$, Carlos Alberto Mendes Moraes ${ }^{d}$ \\ ${ }^{a}$ Núcleo de Caracterização de Materiais (NucMat), Universidade do Vale do Rio dos Sinos (UNISINOS), \\ São Leopoldo, RS, Brasil \\ ${ }^{b}$ Artecola Quimica S.A., Campo Bom, RS, Brasil \\ ${ }^{c}$ Núcleo de Caracterização de Materiais (NucMat), Programa de Pós-Graduação em Engenharia \\ Elétrica, Universidade do Vale do Rio dos Sinos (UNISINOS), São Leopoldo, RS, Brasil \\ ${ }^{d}$ Núcleo de Caracterização de Materiais (NucMat), Programas de Pós-Graduação em Engenharia Civil \\ e Mecânica, Universidade do Vale do Rio dos Sinos (UNISINOS), São Leopoldo, RS, Brasil
}

Received: July 27, 2016; Revised: January 12, 2018; Accepted: February 26, 2018

\begin{abstract}
Since epoxy resins are used as composite matrix with excellent results, and silica is one of the fillers most often employed, this study compared the performance of rice husk ash (RHA) as filler in epoxy composites, in replacement for high-purity silica. Composites were molded containing $20 \%$, $40 \%$, and $60 \%$ (wt) silica or RHA. Viscosity analysis, infrared spectroscopy (IR), thermogravimetric analysis (TGA), differential scanning calorimetry (DSC), scanning electron microscopy (SEM) as well as mechanical and water absorption tests were carried out to evaluate composites. Glass transition temperature after curing and thermal degradation temperature of all samples analyzed were approximately $140^{\circ} \mathrm{C}$ and $370{ }^{\circ} \mathrm{C}$, respectively. RHA and silica exhibited similar mechanical and water absorption characteristics, indicating that rice husk ash may be a suitable replacement for silica. SEM imaging showed good filler dispersion and distribution in the polymer matrix, highlighting the more effective adhesion interface between RHA particles and the matrix.
\end{abstract}

Keywords: rice husk ash, recycling, polymer-matrix composites, epoxy composites.

\section{Introduction}

The risk of scarcity of natural resources and the increasingly severe issues around environmental pollution have highlighted the need for materials with established properties for specific purposes ${ }^{1}$. In this regard, the development of new, low-impact materials is essential in the attempt to minimize environmental problems. The use of recycled materials, apart from byproducts that until recently were considered industrial waste, emerges as an interesting alternative to mitigate environmental issues. Such measures reduce the amount of raw materials extracted from the environment, promoting the use and adding value to waste that otherwise would be disposed of in industrial landfills.

A good example of such environmental effort is the use of rice husk ash (RHA), produced by the combustion of rice husk. RHA accounts for roughly $20 \%$ of the unburnt husk and for $4 \%$ of unmilled rice. Large amounts of RHA are produced in Brazil, especially in the state of Rio Grande do Sul, the country's top producer. Given the 2013-2014 yield and the percentages shown above, if all rice husk were used as biomass to energy generation, almost 500 metric tons of RHA would have been produced in Brazil alone ${ }^{2,3}$.

RHA is composed of silica and carbon, in addition to elements like potassium, phosphorus, calcium, and magnesium, iron, and sodium at trace levels ${ }^{4}$. The high silica content of RHA makes it a potentially interesting admixture with several industrial applications, as in the production of glass, refractory materials, pozzolanic material used in construction, silicon carbide, silicates, and pure silica. In addition, RHA may be used as adsorbent and reinforcing agent or filler in polymer composites ${ }^{5-7}$. Different applications require different processing and purification operations, such as grain size seggregation $^{8}$, milling ${ }^{9}$, and acid leaching ${ }^{10}$.

In recent years, the use of RHA as filler in the formulation of several polymeric materials has become the object of increasing research, especially in rubbers and thermoplastics. Research has consistently underlined the positive performance of RHA as a replacement for other fillers ${ }^{11,12}$. Yet, while most studies have looked into the applicability of RHA as filler in rubbers or thermoplastic polymer composites, the potential of the byproduct as a reinforcing agent in epoxy thermostable polymers has not been established. 
Fillers and reinforcing agents improve electric, mechanical, and thermal properties of composites. They also afford better dimensional control as an alternative to the inferior mechanical resistance and stability typical of ordinary polymers ${ }^{11,13}$. Epoxy polymers are excellent materials to be used as matrix for composites, especially due to good adhesion rates, desirable mechanical and insulating properties, low humidity content, good thermal resistance and retraction, in addition to uncomplicated processing requirements. In addition, the material is widely used in various engineering applications ${ }^{14,15}$. Silica is one of the most commonly used fillers to improve properties such as stiffness and water absorption in epoxy matrix composites, in addition to reducing costs associated with materials. However, the production of silica from sand or ore requires energy-intensive mechanical, physical, chemical, and thermal operations based on high temperatures and large amounts of acids that ultimately generate considerable volumes of chemical waste ${ }^{16}$.

The applications of epoxy-silica composites spread across high-performance industries such as aerospace, automobile, coatings, and electronics, where they are used in the manufacture and printed circuits and in the encapsulation of semiconductors ${ }^{17}$. The role of RHA as polymer reinforcing agent or filler is not new. As a result, considering the high silica level of the material, the replacement of commercial silica used as filler in epoxy composites by RHA could bring several environmental and economic benefits, eliminating impact-intensive processes, reducing energy use, lowering the production of liquid waste, and adding value to a waste by using it as admixture.

The present study evaluated epoxy composites prepared with RHA as filler, and compared the performance of these products with those manufactured with high-purity commercial silica.

\section{Experimental}

\subsection{Materials}

The materials used are available in the market and were used as received, according to the manufacturers' instructions: diglycidyl ether epoxy bisphenol A resin (DGEBA, Araldite GY 260, Huntsman) as matrix, a novolac phenolic resin (SFP643, SI Group) as hardener, 5-methyl-2-phenyl-imidazole (Curezol 1PZ, Air Products) as catalyst, 3-glycidoxi-propyltrimethoxy-silane (Xiameter OFS-6040, Dow-Corning) as coupling agent, and a carnauba wax product (Tec Glaze N, Polinox) as demolding agent.

\subsubsection{Fillers}

Since the combustion process influences the characteristics of the ash produced, two RHAs were tested: one produced in a moving grate reactor (RHA-MG) and one generated in a fluidized bed reactor (RHA-FB). The RHAs were obtained from two companies established in the state of Rio Grande do Sul, Brazil, which use rice husk as biomass for energy generation. RHA-FB was treated and classified according to grain size by the producer company and used as provided. RHA-MG was delivered untreated, so the material was sieved through a $1.2-\mathrm{mm}$ mesh to remove impurities and unburnt rice husk. The passing fraction thereof was then milled in an eccentric ball mill (CB2-T) for $2 \mathrm{~h} 20$ ' to level out particle size. RHA-FB and RHA-MG were compared with two commercial silica powders, a crystalline silica (Shinyo Pure Chemicals Co Ltd.), and one fused amorphous silica (Sibelco Korea Co Ltd.), both of high purity grade. Table 1 shows the properties of the fillers used. The materials were analyzed according to a procedure previously described ${ }^{18}$.

\subsubsection{Filler treatment}

Several studies have highlighted the importance of using a coupling agent in the production of polymer composites ${ }^{19-21}$. Fillers were pretreated wet, and the coupling agent was dissolved (1.5\% wt of the filler percentage) in ethanol and added to the filler. This material was mixed and placed in ultrasonic bath (Ultracleaner Unique 1600A) for $30 \mathrm{~min}$ to remove ethanol by evaporation.

\subsubsection{Composite preparation and molding}

A formulation containing 65\% DGEBA and 35\% novolac phenolic resin was used to prepare all composites. Then, $0.8 \%$ wt carnauba vax was added as demolding agent. Next, three composites were formulated, containing $20 \%, 40 \%$, and $60 \%$ wt of amount of filler used. Mixtures were prepared at approximately $100^{\circ} \mathrm{C}$ in vacuum to remove bubbles. Fillers were added slowly, stirring until obtaining a homogeneous mixture. Finally, $0.5 \%$ wt catalyst was added considering the resin amount. A sample with no filler was prepared for comparison. Composites were casted in a stainless-steel mold (AISI 304) preheated at $110^{\circ} \mathrm{C}$ and previously coated with demolding agent. Composites were cured in a stove at $125^{\circ} \mathrm{C}$ for $2 \mathrm{~h}$.

\subsubsection{Composite characterization}

Viscosity was evaluated using a 20-g sample of the epoxy resin and filler (without the other components) in a viscometer (Brookfield RV DV II, spindle 27) at $100{ }^{\circ} \mathrm{C}$ and $20 \mathrm{rpm}$.

Fourier transform infrared spectroscopy (FTIR) was used to analyze the functional groups that constitute the composites, before and after curing. Spectra were obtained using the reflectance technique with $\mathrm{KBr}$ prism in a spectrometer (IR-Prestige21, Shimadzu), resolved at $2 \mathrm{~cm}^{-1}$ and 30 scans in the $650-4000 \mathrm{~cm}^{-1}$ frequency range.

Differential scanning calorimetry (DSC) was conducted in a calorimeter (Jade DSC, Perkin Elmer) calibrated using an indium standard. Approximately 10-mg non-cured samples were placed in aluminum cartridges hermetically sealed in 
Table 1. Properties of the fillers (RHAs and silicas) investigated in this study

\begin{tabular}{lcccc}
\hline Property & RHA-FB & RHA-MG & Crystalline silica & Fused silica \\
\hline Mean diameter $(\mu \mathrm{m})$ & 19.56 & 19.74 & 19.97 & 23.85 \\
Specific weight $\left({\left.\mathrm{g} \cdot \mathrm{cm}^{-3}\right)}^{-3}\right.$ & 2.22 & 2.20 & 2.69 & 2.27 \\
$\begin{array}{l}\text { Surface area BET } \\
\left(\mathrm{m}^{2} \cdot \mathrm{g}^{-1}\right)\end{array}$ & 11.35 & 39.27 & 0.92 & 2.73 \\
Loss on ignition $(\%)$ & 2.96 & 9.88 & 0.191 & 0.156 \\
$\mathrm{SiO}_{2}(\%)$ & 96.71 & 90.02 & 99.24 & 97.97 \\
Morphology & Amorphous & $\begin{array}{c}\text { Predominantly } \\
\text { amorphous (cristobalite) }\end{array}$ & Crystalline (quartz) & Amorphous \\
\hline
\end{tabular}

a $20-\mathrm{mL} \mathrm{min}^{-1}$ nitrogen flow. In the first scan, samples were kept at $-25^{\circ} \mathrm{C}$ for $2 \mathrm{~min}$ and then heated stepwise to $200^{\circ} \mathrm{C}$ at a $10^{\circ} \mathrm{C} \mathrm{min}^{-1}$. In the second, samples were heated from $0{ }^{\circ} \mathrm{C}$ to $200{ }^{\circ} \mathrm{C}$ at $10{ }^{\circ} \mathrm{C} \mathrm{min}^{-1}$. The enthalpy of the reaction represented as the area under the exothermal peak of the curve was calculated using the proprietary software of the equipment.

Thermogravimetric Analysis (TGA) was used to evaluate the physical and chemical phenomena associated with mass loss of cured composites with temperature in a thermal analysis system (RB-3000-20, BP Engenharia). Samples were placed in a nickel pot and heated from $20^{\circ} \mathrm{C}$ to $1,000{ }^{\circ} \mathrm{C}$ at $10^{\circ} \mathrm{C}$ $\mathrm{min}^{-1}$ in a non-controlled atmosphere.

The compatibility and dispersion of fillers in the composite was evaluated by scanning electron microscopy (SEM) (EVO MA15, Zeiss). High-vacuum backscattered electron images were obtained at $20 \mathrm{kV}$ using polished samples of the composites' inner core.

Tensile properties of the materials were analyzed following the ASTM D638 ${ }^{22}$ in a universal tensile testing machine (MTS Landmark) at $1.2 \mathrm{~mm} \mathrm{~min}^{-1}$. Five repeats were carried out for each experimental condition and the results are presented as averages of the values.

Water absorption was evaluated following the procedure described in ASTM D57023. Cured samples were dried in a stove at $50 \pm 3{ }^{\circ} \mathrm{C}$ for $24 \mathrm{~h}$. Then, they were immersed in distilled water at $23{ }^{\circ} \mathrm{C}$ for $24 \mathrm{~h}$. The results are expressed as percent weight increase.

\section{Results and Discussion}

Figure 1 illustrates the effect of increased filler amounts on viscosity of mixtures used to prepare the composites.

The results clearly indicate the direct correlation between higher viscosity values and increased filler amounts. In a previous study, this increase in viscosity was credited to the fact that filler particles act as an obstacle to the flow of resins $^{24}$. In the present study, the viscosity values of mixtures prepared with $20 \%$ and $40 \%$ of fused silica and RHAs were quite similar. However, the mixture prepared with $60 \%$ RHAs exhibited a marked increase in viscosity. As a rule, the use of silica as filler did not influence viscosity values as consistently as the use of RHAs. Adding RHAs caused an exponential increase in viscosity, while using crystalline silica induced a linear increase in values. The incorporation of fillers into polymers may improve mechanical and thermal properties of composites, but only to a certain point, after the higher viscosity of mixtures obtained makes processing operations more complex. This difficulty was clearly observed in the present experiment, when mixtures containing silica as filler were significantly more viscous, rendering unfeasible the processing of materials, especially when $60 \%$ silica was added. Viscosity is affected by a variety of characteristics of filler particles, such as geometry, size, chemical structure, and surface $\operatorname{area}^{25}$. In this sense, it may be assumed that the larger surface area of RHA particles is behind the high viscosity value observed for the mixture prepared with $60 \%$ of the material. Similarly, increasing crystalline silica percentages elicited a linear rise in viscosity. However, fused silica and RHAs induced an exponential growth in the property, possibly due to the predominantly amorphous - and therefore more reactive - structure of these fillers.

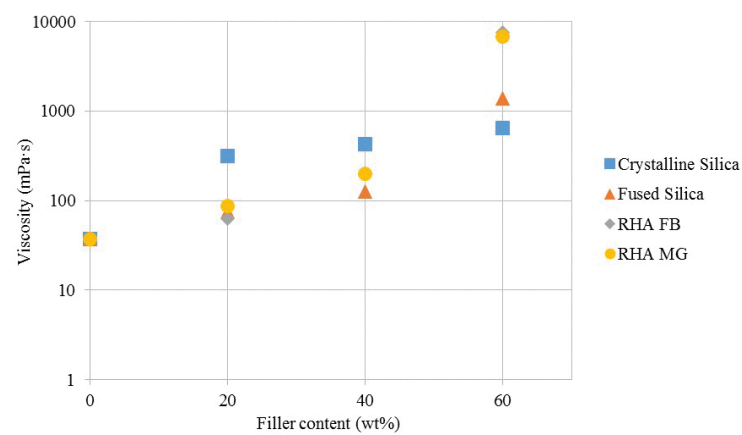

Figure 1. Effect of filler amount on the viscosity of mixtures (m Pa s)

Figure 2 presents the spectra obtained before curing for the pure epoxy resin (DGEBA), the pure phenolic resin, and the $0 \%$ filler mixture. The pure epoxy resin spectrum had the typical absorption bands observed for an epichlorohydrin and bisphenol A epoxy resin. An absorption band characteristic of the $\mathrm{OH}$ bond is clearly seen between 3600 and $3200 \mathrm{~cm}^{-1}$. Yet, the peak observed is short, due to the low numbers of $\mathrm{OH}$ groups in this resin's molecule. The $914 \mathrm{~cm}^{-1}$ band (in the 
950 to $860 \mathrm{~cm}^{-1}$ range) indicates the epoxy group, while the $1100 \mathrm{~cm}^{-1}$ peak points to the presence of an aromatic ether group $^{26}$. The spectrum obtained for the phenolic resin shows a wide $\mathrm{OH}$ band between 3600 and $3200 \mathrm{~cm}^{-1}$, which is closely followed by low peaks indicating the aromatic $\mathrm{CH}$ bonds. $\mathrm{A}$ typical band of the aromatic $\mathrm{C}=\mathrm{C}$ bond is seen at $1600 \mathrm{~cm}^{-1}$, while a wide and intense band indicating the $\mathrm{C}-\mathrm{O}$ bond is observed at approximately $1200 \mathrm{~cm}^{-1}$. Different C-H bonds are signaled between 1100 and $650 \mathrm{~cm}^{-12} 6$. The spectrum obtained for the $0 \%$ filler mixture is a combination of the spectra of the epoxy and phenolic resins.

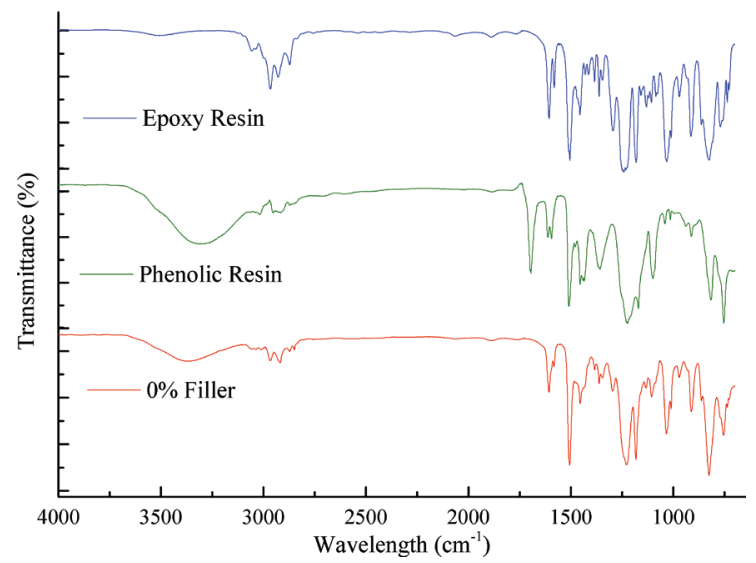

Figure 2. FTIR spectra of the epoxy resin, phenolic resin, and $0 \%$ filler mixture

Figures 3 and 4 show the spectra obtained for the composites prepared with $20 \%, 40 \%$, and $60 \%$ of fillers crystalline silica and RHA-FB, respectively, before cure. These spectra are shown for the sake of exemplification, since all spectra were essentially similar. The spectra shown are similar to that obtained for the $0 \%$ filler mixture. Nevertheless, as filler proportion increases, the band near $1100 \mathrm{~cm}^{-1}$ (which indicates the Si-O bond) increases and superimposes onto the bands at the low-frequency end of the spectra of resins. Figure 5 shows the spectrum for the $0 \%$ filler material before and after curing. From the molecular standpoint, curing takes place when the aromatic ring breaks open, reacting with the phenolic $\mathrm{OH}$ group and forming an aromatic ether bond. This transformation is reflected in the fading of the epoxy band at $914 \mathrm{~cm}^{-1}$, the shorter $\mathrm{OH}$ band at $3400 \mathrm{~cm}^{-1}$, and the increase in the aromatic ether band at $1100 \mathrm{~cm}^{-1}$. This curing mechanism (that is a polymerization reaction catalyzed by 5-methyl-2-phenyl-imidazole) has been described in the literature ${ }^{19}$.

The thermograms obtained by DSC of the composites before and after curing are shown in Figures 6 and 7. Table 2 shows the glass transition temperature ( $\mathrm{Tg}$ ) before and after curing, the peak temperature, and the reaction enthalpy of mixtures obtained from thermograms.

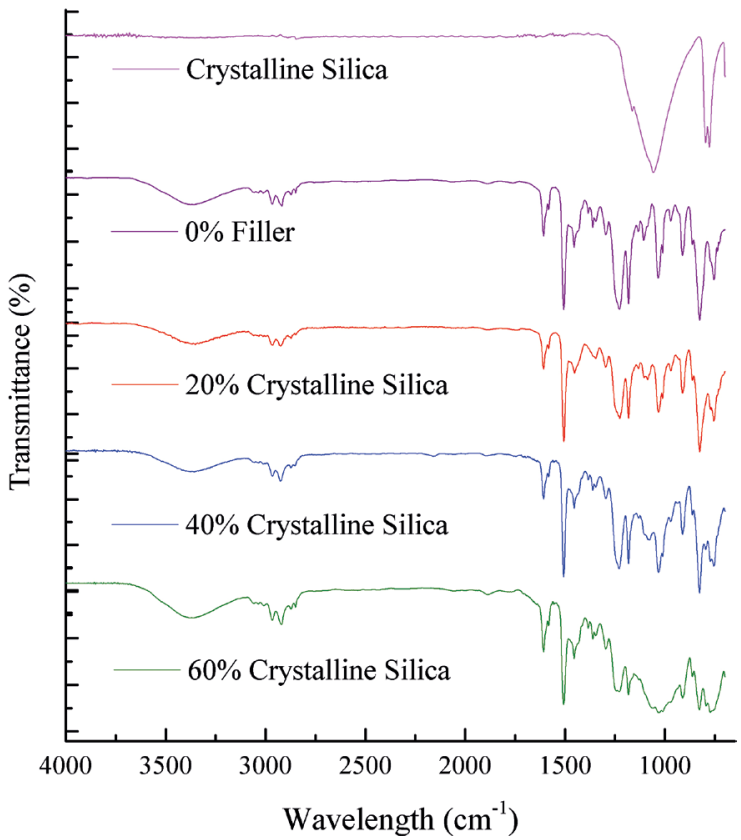

Figure 3. FTIR spectrum for the mixtures prepared with 20, 40, and $60 \%$ (wt) crystalline silica

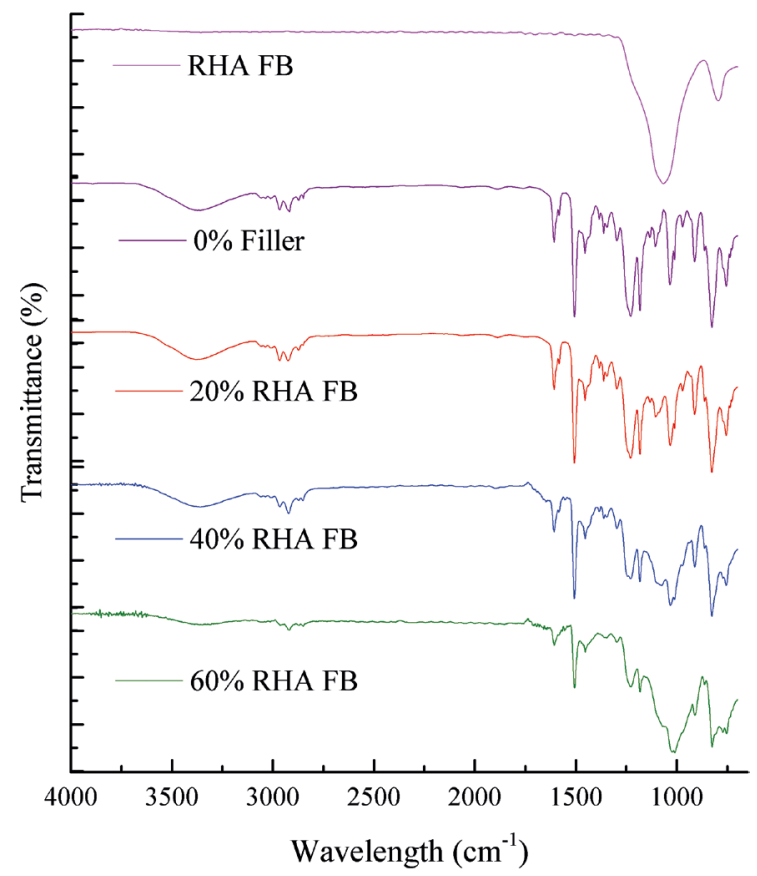

Figure 4. FTIR spectrum for the mixtures prepared with 20, 40, and $60 \%$ (wt) RHA-FB

No endothermic peaks were observed in the samples analyzed, indicating no vaporization of water, additives, or other volatiles. All samples had exothermic peaks, which are associated with the epoxy resin curing reaction. Two starter mechanisms have been described when 5-methyl-2-phenylimidazole is used as catalyzer. The first includes a primary 


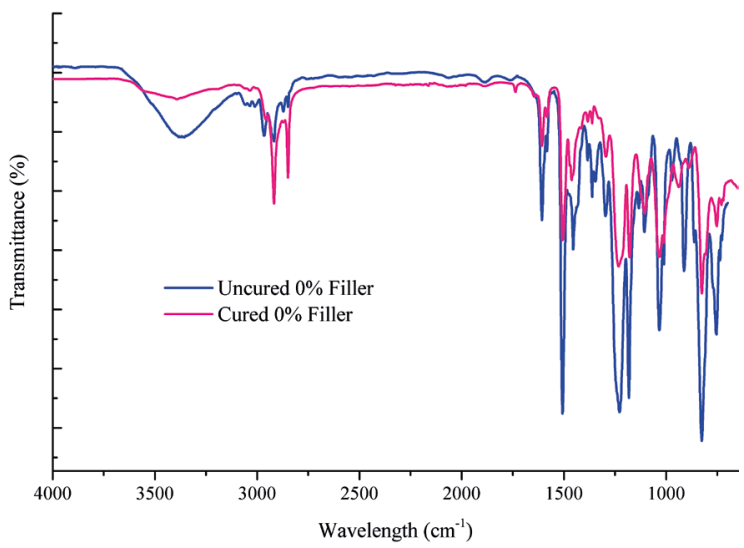

Figure 5. FTIR spectrum for the mixture with $0 \%$ filler mixture before and after curing

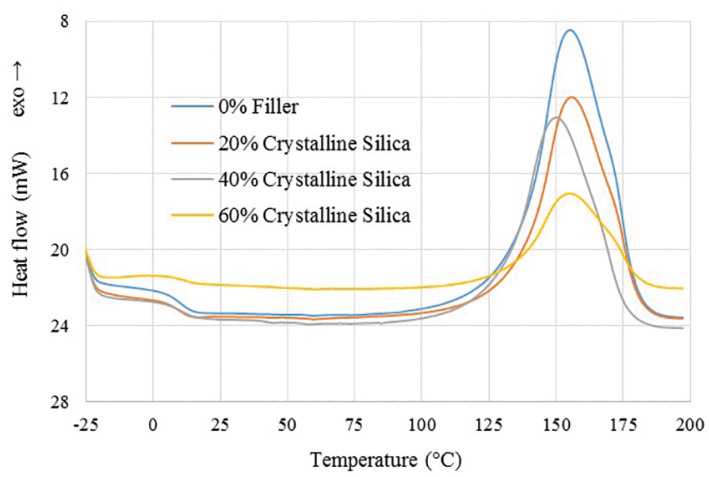

Figure 6. DSC of the composites prepared with 20,40 , and $60 \%$ (wt) crystalline silica

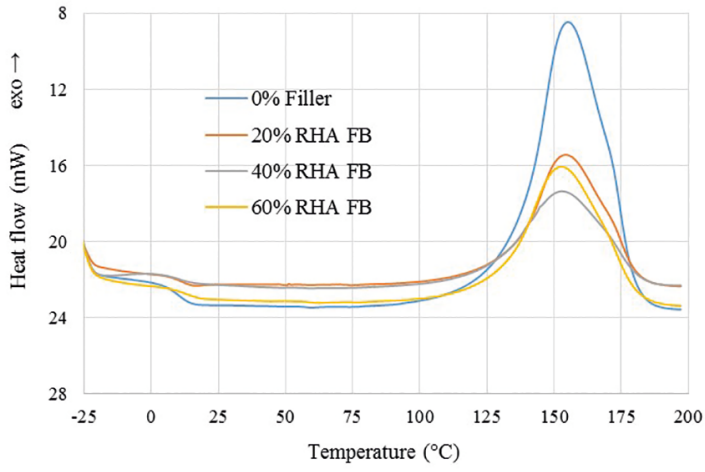

Figure 7. DSC of the composites prepared with 20,40 , and $60 \%$ (wt) RHA-FB

linear reaction between the epoxy ring and the catalyzer. The second is the reaction between the phenolic $\mathrm{OH}$ group and the catalyzer ${ }^{19}$. Therefore, the 'shoulder' observed in some DSC curves is due to these starter mechanisms, since the catalyst used reacts with the epoxy and the phenolic rings alike. A step is observed near $10^{\circ} \mathrm{C}$ (Figures 6 and 7), which represents chain mobility ${ }^{27} . \mathrm{Tg}$ is an important parameter considering material storage. Taking into account temperatures below the $\mathrm{Tg}$, the material retains its viscoelastic properties and avoid possible partial crosslinking reactions, improving product's shelf-life ${ }^{28}$. The Tg values of the cured composites (Table 2) were around $140^{\circ} \mathrm{C}$, which may be too high for an epoxy polymer. $\mathrm{Tg}$ is a function of the material's chemical structure and degree of crosslinking. Predominantly linear, more flexible polymer chains mean that the final product will have comparatively lower Tg. For a cured polymer, $\mathrm{Tg}$ is also linked with chemical and thermal resistance: the higher the $\mathrm{Tg}$ value, the more resistant the material ${ }^{27}$. In the present study, Tg measured before and after curing as well as maximum reaction temperatures did not seem to be significantly influenced by the type and amount of filler added. Since the DSC profiles of the samples analyzed were similar, it is possible to conclude that the different proportions of RHAs and silica types used as filler in the present study did not affect the thermal characteristics and the curing mechanism of the materials tested. With increasing filler levels, reaction enthalpy drops as the amount of polymer available for a reaction is proportionally smaller. Here, the reaction enthalpy for the $0 \%$ filler mixture was $-279 \mathrm{~J} \mathrm{~g}^{-1}$, decreasing with the addition of fillers and reaching the value of $-79.6 \mathrm{~J} \mathrm{~g}^{-1}$ for the $60 \%$ RHA-MG.

The thermogravimetric analysis was carried out after curing (Figures 8 and 9). Table 3 shows the main critical limits considered relevant for the composites.

The initial degradation temperature of all samples was at around $370{ }^{\circ} \mathrm{C}$. In the temperature range of $110^{\circ} \mathrm{C}$ to $280{ }^{\circ} \mathrm{C}$, a small mass loss of between $0.50 \%$ and $0.98 \%$ was observed for the samples prepared with $20 \%$ and $40 \%$ of fillers, possibly due to the elimination of low molecular weight volatiles or humidity. Epoxy and phenolic resins underwent thermal decomposition over $400{ }^{\circ} \mathrm{C}$, when mass loss values were the highest for all samples. Mass loss at temperatures over $300{ }^{\circ} \mathrm{C}$ have been associated with the decomposition of the epoxy matrix itself ${ }^{29}$. Independently of the amount of filler added, the samples analyzed remained stable at temperatures nearing $400{ }^{\circ} \mathrm{C}$, showing that the addition of fillers neither influenced nor improved thermo-oxidative properties of materials. Except for total mass loss, the samples exhibited similar thermogravimetric profiles. Mass loss is known to decrease with increasing amounts of fillers, since these are predominantly non-reactive. Total mass loss of the $0 \%$ filler mixture was $84.23 \%$, decreasing with the growing amounts of fillers used and reaching $31.25 \%$ for the mixture prepared with $60 \%$ fused silica. Since RHAs are richer in carbon content, in particular the RHA-MG, the thermograms of the composites prepared with different amounts of RHAs presented higher mass loss when compared with those prepared with silica. Previous studies that analyzed epoxy composites prepared with small amounts of RHA (of up to 5\%) reported similar degradation behavior as that observed in the present work, also at one stage only and at temperature above $300^{\circ} \mathrm{C}^{30,31}$. For the authors of these works, such behavior indicates the 
Table 2. DSC parameters of mixtures prepared with $0 \%$ filler different proportions of crystalline silica, fused silica, RHA-FB, and RHA-MG

\begin{tabular}{lcccc}
\hline Sample & $\mathbf{T g}\left({ }^{\circ} \mathbf{C}\right)$ & Tg after cure $\left({ }^{\circ} \mathbf{C}\right)$ & T max $\left({ }^{\circ} \mathbf{C}\right)$ & Enthalpy $\left.(\mathbf{J . g})^{-1}\right)$ \\
\hline 0\% Filler & 10.1 & 137.6 & 155.2 & -279.0 \\
20\% Crystalline silica & 8.9 & 137.9 & 155.7 & -211.1 \\
20\% Fused silica & 8.6 & 138.1 & 155.3 & -203.0 \\
$20 \%$ RHA-FB & 10.3 & 139.9 & 154.3 & -221.8 \\
20\% RHA-MG & 12.0 & 141.8 & 153.2 & -212.6 \\
$40 \%$ Crystalline silica & 10.0 & 141.5 & 150.2 & -159.8 \\
$40 \%$ Fused silica & 11.1 & 140.3 & 156.4 & -150.1 \\
$40 \%$ RHA-FB & 9.8 & 142.5 & 153.1 & -129.0 \\
$40 \%$ RHA-MG & 11.7 & 139.6 & 156.5 & -136.4 \\
$60 \%$ Crystalline silica & 11.1 & 141.0 & 155.1 & -106.5 \\
$60 \%$ Fused silica & 13.2 & 143.8 & 152.3 & -101.9 \\
$60 \%$ RHA-FB & 13.0 & 149.0 & 152.8 & -98.3 \\
$60 \%$ RHA-MG & 15.0 & 140.5 & 151.7 & -79.6 \\
\hline
\end{tabular}

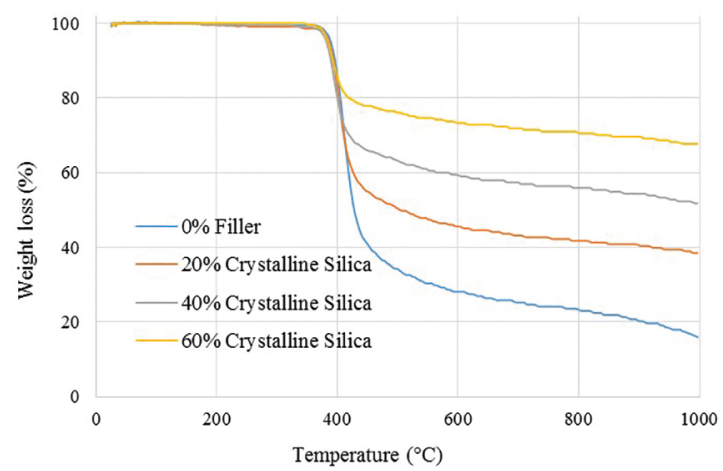

Figure 8. Thermogravimetric analysis of the mixtures prepared with 20,40 , and $60 \%$ (wt) crystalline silica

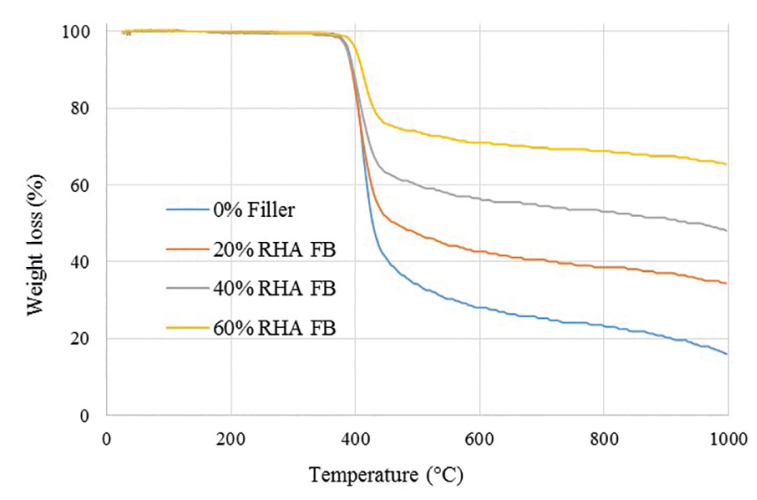

Figure 9. Thermogravimetric analysis of the mixtures prepared with 20,40 , and $60 \%$ (wt) RHA-FB

Table 3. Critical limits of the thermogravimetric analysis of composites

\begin{tabular}{|c|c|c|c|}
\hline \multirow{2}{*}{ Sample } & \multicolumn{3}{|c|}{$\Delta \mathrm{m}(\% \mathrm{wt})$} \\
\hline & $\approx 110-280^{\circ} \mathrm{C}$ & $\approx 280-560^{\circ} \mathrm{C}$ & Total \\
\hline $0 \%$ Filler & 0.66 & 69.10 & 84.23 \\
\hline 20\% Crystalline silica & 0.94 & 51.32 & 61.61 \\
\hline 20\% Fused silica & 0.61 & 50.91 & 62.43 \\
\hline $20 \%$ RHA-FB & 0.60 & 55.65 & 65.94 \\
\hline $20 \%$ RHA-MG & 0.98 & 55.87 & 66.44 \\
\hline $40 \%$ Crystalline silica & 0.50 & 38.30 & 48.20 \\
\hline 40\% Fused silica & 0.50 & 37.04 & 45.83 \\
\hline $40 \%$ RHA-FB & 0.51 & 41.79 & 52.01 \\
\hline $40 \%$ RHA-MG & 0.91 & 41.36 & 51.82 \\
\hline $60 \%$ Crystalline silica & & 25.33 & 32.44 \\
\hline $60 \%$ Fused silica & & 24.06 & 31.25 \\
\hline $60 \%$ RHA-FB & & 27.73 & 34.65 \\
\hline $60 \%$ RHA-MG & & 28.48 & 36.29 \\
\hline
\end{tabular}


absence of volatiles such as water or solvents. The percent total mass loss observed in those investigations was higher than the percent amount of fillers used, possibly due to the partially ionic character and high binding energy of the $\mathrm{Si}-\mathrm{O}-\mathrm{Si}$ bonds in silica molecules, which delays thermal degradation.

SEM analyses were carried out to evaluate the dispersion of fillers in the polymer matrix (Figures 10, 11, 12, and 13).
The properties of filler play an important role in the distribution of particles in the matrix. However, it is the combined effect of the characteristics of matrix and filler that rules the dispersion of fillers in the product. The SEM images of polished composites analyzed in the present study confirm the good dispersion of fillers in the polymer matrix. The exception was composites containing fused silica, whose particles looked crammed in some points, pointing to some
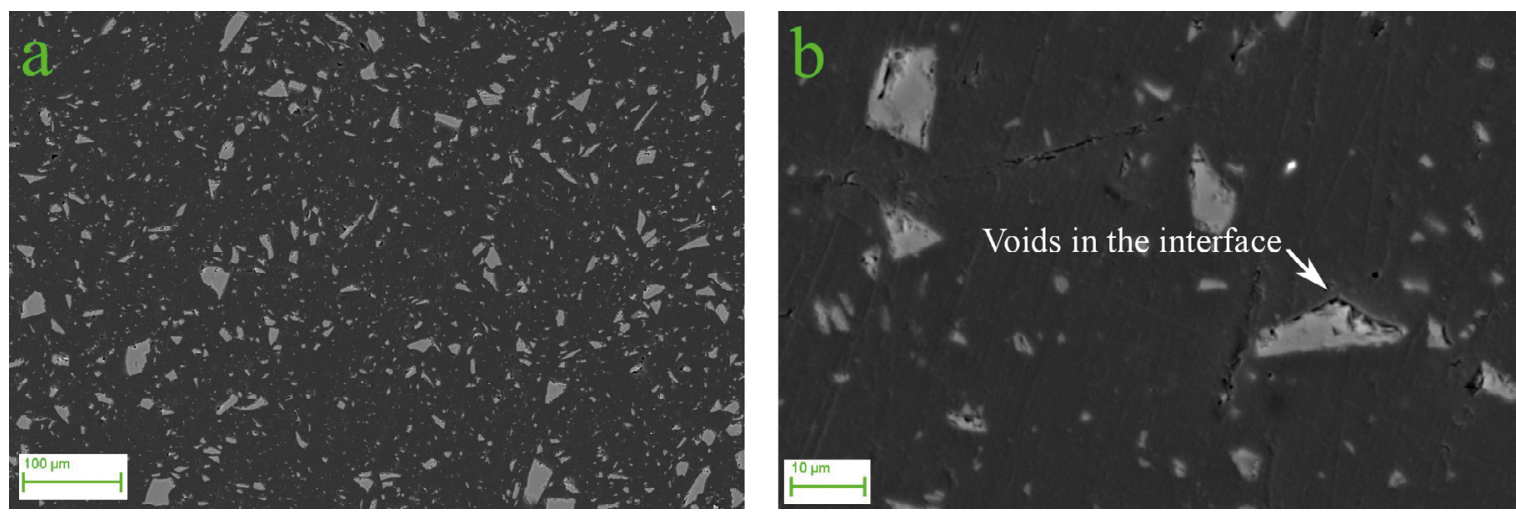

Figure 10. SEM microphotograph of a sample containing 20\% (wt) crystalline silica Bars: A - $100 \mu \mathrm{m}$; B - $10 \mu \mathrm{m}$
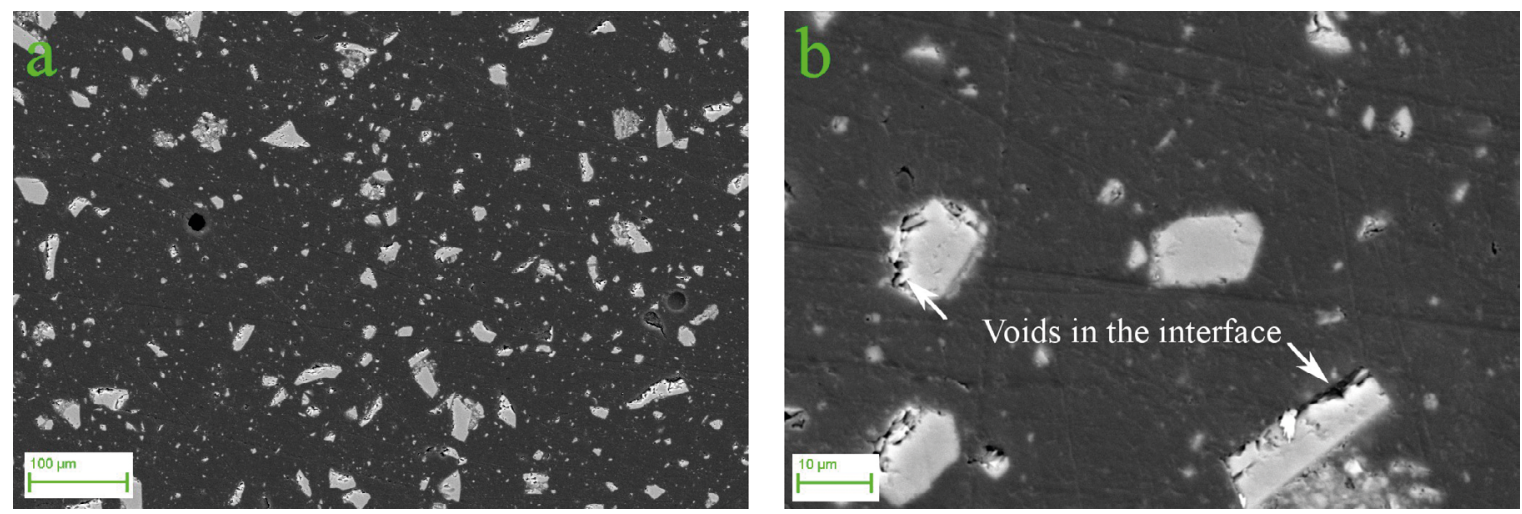

Figure 11. SEM microphotograph of a sample containing $20 \%$ (wt) fused silica Bars: A - $100 \mu \mathrm{m}$; B - $10 \mu \mathrm{m}$
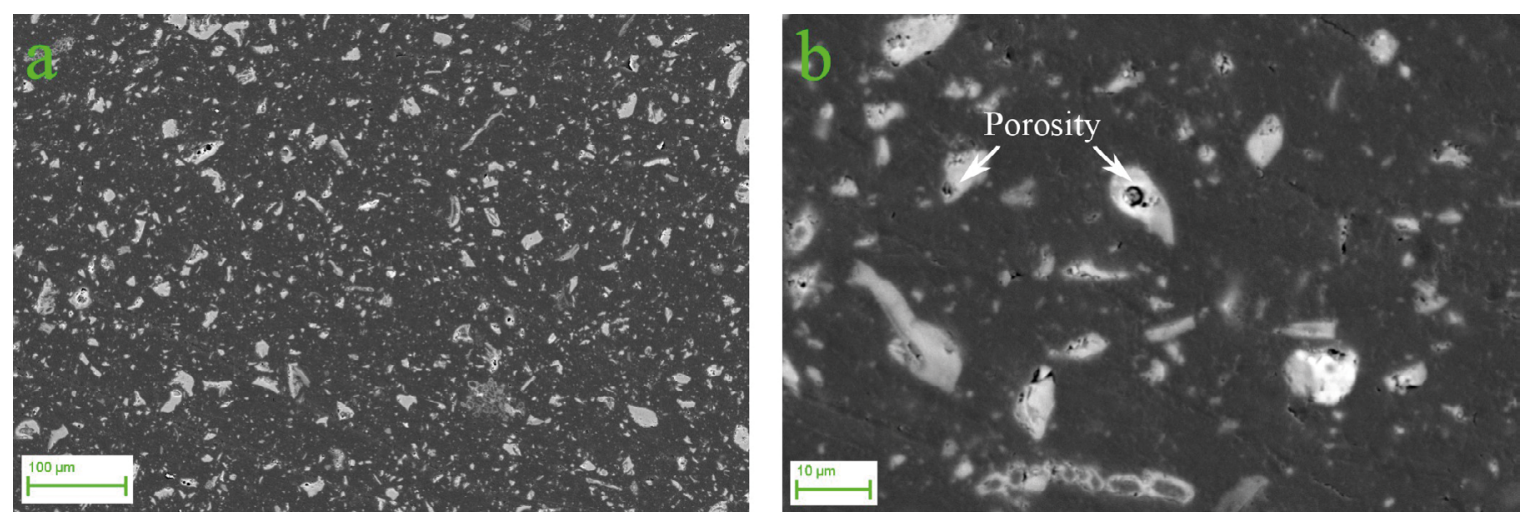

Figure 12. SEM microphotograph of a sample containing 20\% (wt) RHA-FB Bars: A - $100 \mu \mathrm{m}$; B - $10 \mu \mathrm{m}$ 

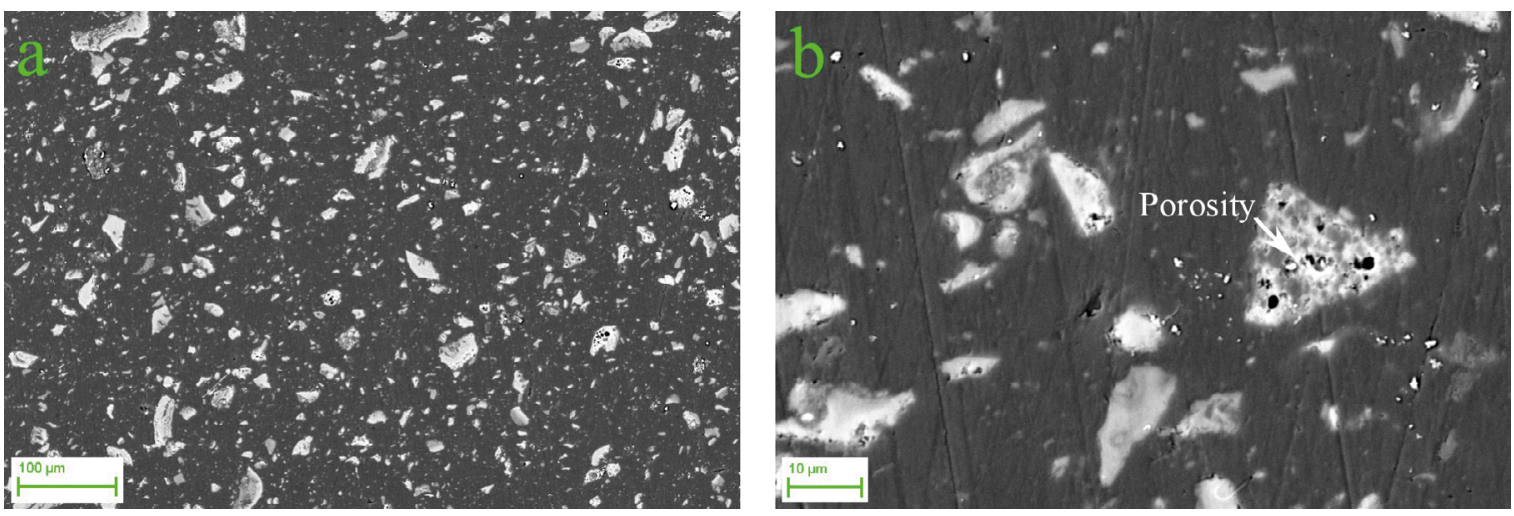

Figure 13. SEM microphotograph of a sample containing 20\% (wt) RHA-MG Bars: A - $100 \mu \mathrm{m}$; B - $10 \mu \mathrm{m}$

degree of incompatibility between this filler and the matrix, though with no significant consequence to most of the properties of the material evaluated. The adhesion interface between filler and matrix particles may explain the better performance of composites prepared with RHA. The SEM microphotographs of samples prepared with crystalline and fused silicas (Figures 10b and 11b) reveal the existence of voids in the filler-matrix interface. This phenomenon was not observed in composites prepared with RHAs, indicating that these fillers enjoy better compatibility with polymers, possibly due to the higher levels of carbon and the apolar character of the materials. In addition, this improved performance may be associated with the larger surface area of RHAs, which is directly correlated with the number of silanol groups on that site. As the SEM microphotographs of RHA composites show, however, even though this filler shows improved contact surface, considerable depressions caused by the porosity of RHAs are observed. Pore size influences the absorption of polymer molecules, since the steric effect typical of long chains prevents pores from being filled ${ }^{32}$.

Figure 14 shows the results of the tensile tests. Figure 15 exhibits the values of elastic modulus obtained.

Increasing filler proportions caused an increase in elastic modulus and a drop in tensile strength of composites. A previous study has shown that the addition of fillers to polymer matrixes normally reduces elongation at rupture ${ }^{24}$. The

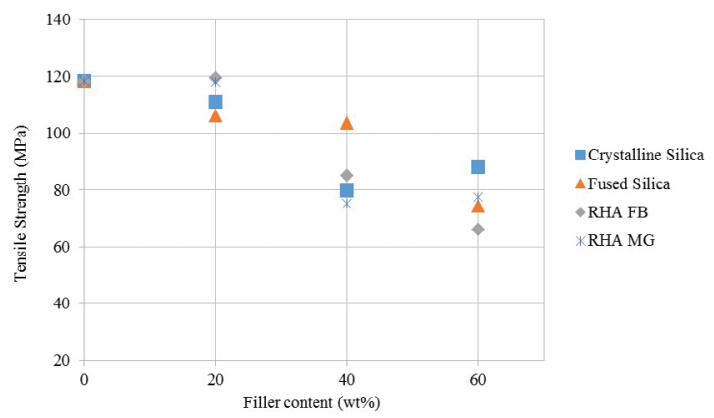

Figure 14. Tensile strength of composites (MPa). Notice the increased load level at breaking point

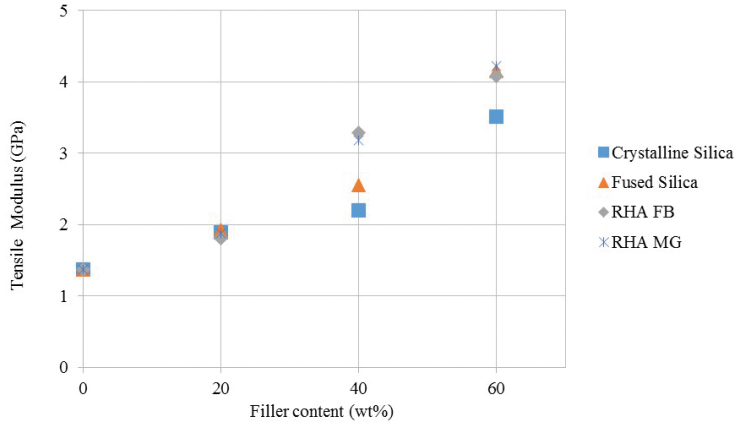

Figure 15. Elasticity modulus of composites (GPa). Effect of the percentage of filler on the elasticity modulus under tensile strength

mechanical properties of composites are affected by several factors, mainly homogeneity of the material, dispersion and distribution of fillers in the matrix, compatibility between filler and matrix, in addition to specific filler characteristics such as full size of particles and particle size distribution ${ }^{25}$. Independently of the type of filler used, values of tensile strength and elastic modulus were quite similar between composites prepared with $20 \%$ of filler, though composites made with RHA presented slightly higher tensile strength values. When the proportion of filler is increased to $40 \%$, tensile strength of RHA composites is lower than that of silica composites, while elasticity modulus values increase. Similar results were observed when the proportion of filler was risen to $60 \%$. This finding may be explained based on the porous morphology of RHAs, which is less resistant when compared with the solid morphology of the silica types tested, let alone the fact that such morphologic arrangement prevents the entry of polymer molecules. In other words, the higher the amounts of filler used, the greater the probability of fractures at weak points.

The results of the water absorption tests are shown in Figure 16.

Water absorption of composites decreased with the addition of all proportions of the fillers investigated in the present study. In a study that evaluated the effect of smaller filler proportions $(0.5 \%, 1 \%$, and $1.5 \%)$ the authors also observed 


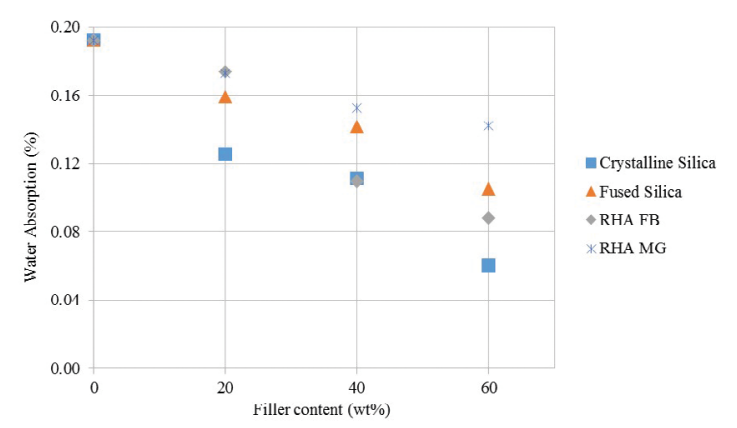

Figure 16. Effect of increasing proportions of filler on water absorption of composites (\%)

that water absorption drops with increasing filler amounts, explaining that this may be due to the inherent hydrophobic nature of the crosslinking formed when silica is added and during the epoxy curing reaction ${ }^{31}$. Poor water absorption is a very important characteristic in various epoxy applications. Percent water absorption values in the present work were similar for composites prepared with all fillers tested, more particularly between those made using crystalline silica and RHA-FB. The lowest water absorption value was observed for composites prepared with crystalline silica $60 \%$, followed by RHA-FB, fused silica, and RHA-MG. The large surface area of RHA-FB $\left(\sim 11 \mathrm{~m}^{2} \mathrm{~g}^{-1}\right)$, compared with that of crystalline and fused silica ( $\sim \mathrm{m}^{2} \mathrm{~g}^{-1}$ and $2.7 \mathrm{~m}^{2} \mathrm{~g}^{-1}$, respectively) did not influence water absorption. In turn, the larger surface area of RHA-MG $\left(\sim 39.3 \mathrm{~m}^{2} \mathrm{~g}^{-1}\right)$ may have increased water absorption of composites prepared with this filler.

\section{Conclusions}

RHA behaved similarly to crystalline silica in most tests, indicating that it can be used as replacement of silica with little loss of properties. The tensile strength and water absorption values were around the same order of magnitude, though RHA composites exhibited better values in general. SEM analysis showed that filler particles distributed well into the polymer matrix. The adhesion interface between filler particles and polymer matrix was more effective when RHA was used, though some voids associated with porosity of this material were observed.

Viscosity values revealed that viscosity of mixtures prepared with RHAs increases exponentially with the proportion of filler added $(60 \%)$, pointing to the risk of problems in processing operations, depending on the application of composites. In this sense, alternative methods to control and reduce viscosity should be considered when high proportions of RHA are used. Overall, lower amounts of RHA (20\% and 40\%) produce composites with properties that are comparable to those prepared with commercial silica as filler.

\section{Acknowledgments}

The authors acknowledge the company Artecola Química S.A. where this work was partially developed, CAPES (Coordination of the Improvement of Higher Education Personnel), FAPERGS (Foundation for Research Support of Rio Grande do Sul) and CNPq (National Council for Scientific and Technological Development) for financial support and scholarship for the researchers.

\section{References}

1. Yang HS, Kim HJ, Son J, Park HJ, Lee BJ, Hwang TS. Ricehusk flour filled polypropylene composites; mechanical and morphological study. Composite Structures. 2004;63(3-4):305312 .

2. Pouey MTF. Beneficiamento da cinza de casca de arroz residual com vistas à produção de cimento composto elou pozolânico. [PhD Thesis]. Porto Alegre: Universidade Federal do Rio Grande do Sul; 2006.

3. Food and Agriculture Organization of the United Nations Statistics - FAOSTAT. Food and Agricultural commodities production/Countries by commodity. Rome: FAO; 2014. Available from: <http://faostat3.fao.org/browse/rankings/ countries_by_commodity/E $>$. Access in: 30/01/2015.

4. Armesto L, Bahill A, Veijonen K, Cabanillas A, Otero J. Combustion behavior of rice husk in a bubbing fluidised bed. Biomass and Bioenergy. 2002;23(3):171-179.

5. Soltani N, Bahrami A, Pech-Canul MI, González LA. Review on the physicochemical treatments of rice husk for production of advanced materials. Chemical Engineering Journal. 2015;264:899-935.

6. Moraes CA, Fernandes IJ, Calheiro D, Kieling AG, Brehm FA, Rigon MR, et al. Review of the rice production cycle: by-products and the main applications focusing on rice husk combustion and ash recycling. Waste Management \& Research. 2014;32(11):1034-1048.

7. Foletto LF, Hoffmann R, Hoffmann RS, Portugal Jr UL, Jahn SL. Aplicabilidade das cinzas da casca de arroz. Química Nova. 2005;28(6):1055-1060.

8. Kieling AG. Influência da segregação no desempenho de cinzas de casca de arroz como pozolanas e material adsorvente. [MSc dissertation]. São Leopoldo: Universidade do Vale do Rio dos Sinos; 2009.

9. Evaldt DC. Influência do uso de aditivos na moagem de cinzas de casca de arroz para sua adequação como coproduto. [MSc dissertation]. São Leopoldo: Universidade do Vale do Rio dos Sinos; 2011.

10. Vayghan AG, Khaloo AR, Rajabipour F. The effects of a hydrochloric acid pre-treatment on the physicochemical properties and pozzolanic performance of rice husk ash. Cement and Concrete Composites. 2013;39:131-140. 
11. Ferro WP, Silva LGA, Wiebeck H. Uso da cinza da casca de arroz como carga em matrizes de poliamida 6 e poliamida 6.6. Polímeros. 2007;17(3):240-243.

12. Azadi M, Bahrololoom ME, Heidari F. Enhancing the mechanical properties of an epoxy coating with rice husk ash, a green product. Journal of Coatings Technology and Research. 2011;8(1):117-123.

13. Fu SY, Feng XQ, Lauke B, Mai YW. Effects of particle size, particle/matrix interface adhesion and particle loading on mechanical properties of particulate-polymer composites. Composites Part B: Engineering. 2008;39(6):933-961.

14. Faruk O, Bledzki AK, Fink HP, Sain M. Biocomposites reinforced with natural fibers: 2000-2010. Progress in Polymer Science. 2012;37(11):1552-1596.

15. Bray DJ, Dittanet P, Guild FJ, Kinloch AJ, Masania K, Pearson RA, et al. The modelling of the toughening of epoxy polymers via silica nanoparticles: The effects of volume fraction and particle size. Polymer. 2013;54(26):7022-7032.

16. Haus R, Prinz S, Priess C. Assessment of High Purity Quartz Resources. In: Götze J, Möckel R, eds. Quartz: Deposits, Mineralogy and Analytics. Berlin: Springer Geology; 2012. p. 29-51.

17. Ponyrko S, Kobera L, Brus J, Matejka L. Epoxy-silica hybrids by nonaqueous sol-gel process. Polymer. 2013;54(23):6271-6282.

18. Fernandes IJ. Desenvolvimento e caracterização de compósitos de cinza de casca de arroz em matriz epóxi. [MSc Dissertation]. São Leopoldo: Universidade do Vale do Rio dos Sinos; 2015.

19. Heo GY, Park SJ. Effect of coupling agents on thermal, flow, and adhesion properties of epoxy/silica compounds for capillary underfill applications. Powder Technology. 2012;230:145-150.

20. Khalil R, Chryss AG, Jollands M, Bhattacharya S. Effect of coupling agents on the crystallinity and viscoelastic properties of composites of rice hull ash-filled polypropylene. Journal of Materials Science. 2007;42(24):10219-10227.

21. Kim WG, Ryu JH. Physical properties of epoxy molding compound for semiconductor encapsulation according to the coupling treatment process change of silica. Journal of Applied Polymer Science. 1997;65(10):1975-1982.
22. ASTM International. ASTM D638-10 - Standard Test Method for Tensile Properties of Plastics. West Conshohocken: ASTM International; 2010.

23. ASTM International. ASTM D570-98(2010)e1 - Standard Test Method for Water Absorption of Plastics. West Conshohocken: ASTM International; 2010.

24. Suwanprateeb J, Hatthapanit K. Rice-husk-ash-based silica as a filler for embedding composites in electronic devices. Journal of Applied Polymer Science. 2002;86(12):3013-3020.

25. Khalil R. Impact of the surface chemistry of rice hull ash on the properties of its composites with polypropylene. [ $\mathrm{PhD}$ Thesis]. Melbourne: Melbourne University; 2008.

26. Silverstein RM, Webster FX, Kiemle D. Spectrometric Identification of Organic Compounds. $7^{\text {th }}$ ed. Hoboken: John Wiley and Sons; 2005.

27. Petrie EM. Epoxy Adhesive Formulations. New York: McGrawHill; 2006.

28. Rabilloud G. Adhesives in Electronics. In: Cognard P, ed. Handbook of Adhesives and Sealants. Oxford: Elsevier; 2005. p. 233-302.

29. Suave J, Coelho LAF, Amico SC, Pezzin SH. Effect of sonication on thermo-mechanical properties of epoxy nanocomposites with carboxylated-SWNT. Materials Science and Engineering: $A$. 2009;509(1-2):57-62.

30. Prabunathan P, Sethuraman K, Alagar M. Development of bio-based F-SBA-15 reinforced epoxy nanocomposites for low-k dielectric applications. High Performance Polymers. 2014;26(3):283-289.

31. Kanimozhi K, Sethuraman K, Selvaraj V, Alagar M. Development of rice husk ash reinforced bismaleimide toughened epoxy nanocomposites. Frontiers in Chemistry. 2014;2:65.

32. Kaewsakul W. Silica-Reinforced Natural Rubber for Low Rolling Resistance, Energy-Saving Tires: Aspects of Mixing, Formulation and Compatibilization. [PhD Thesis]. Enschede/ Pattani: University of Twente and Prince of Songkla University; 2013. 